\title{
BUILT HERITAGE USE AND COMPATIBILITY EVALUATION METHODS: TOWARDS EFFECTIVE DECISION MAKING
}

\author{
ANTHOULA KONSTA \\ ABC Department, Politecnico di Milano, Italy
}

\begin{abstract}
Built heritage use can be seen as both an occasion and an impediment for its conservation; while an appropriate use of built heritage is necessary for the promotion of its cultural values and for its preservation, an incompatible use or a series of interventions for the satisfaction of the user's requirements can provoke damages and lead to its loss. During the last few years, different methodologies for use compatibility have been developed in order to measure and evaluate the impacts on cultural heritage caused by the user's requirements, providing in this way an evidence base for decision-making. This paper provides a literature review of these methods with the purpose of analysing their different approaches, underlining their particulate aspects, and reflecting upon their possible advancement.

Keywords: built heritage use, integration of conservation and valorisation activities, building needs, user requirements, compatibility evaluation methods, efficient and effective conservation.
\end{abstract}

\section{INTRODUCTION}

Built heritage use can be seen as both an occasion and an impediment for its conservation; while an appropriate use of built heritage is necessary for the promotion of its cultural values and for its preservation, an incompatible use or a series of interventions for the satisfaction of the user's requirements can provoke damages and lead to its loss.

In this perspective, conservation recommendations and guidelines as well as best practices and research suggest the integration of conservation and use/valorisation activities. The management of use becomes in this way, a means of a more efficient and effective conservation of built heritage. This implies on the one hand, the understanding of the needs of the building, the identification of its limitations as well as its potentialities, and on the other hand, the understanding of people expectations. The analysis and evaluation of these two aspects aims at the development of possible solutions and the selection of the one that better matches user requirements to what a building can realistically provide [1].

As easily can be understood this kind of operation involves a large number of factors that have to be taken into consideration and requests a holistic vision of the problem in order to be effective. In fact, the application of formal analysis and evaluation frameworks, during the last decade, in the field of cultural heritage has contributed to a more rational and transparent process dealing with complexity.

This paper provides a literature review of the methods above, with the purpose to analyse their different approaches - depending on the urban or building scale of analysis, the occupancy or not of the buildings, the private or public use - to underline their particulate aspects, and to reflect on their possible advancement.

\section{THE USE COMPATIBILITY APPROACH TO THE PROJECT EVALUATION}

As it was pointed out by Della Torre [2] during the conference on compatibility in 2003 there are two different approaches to the compatibility concept, as a requirement of the addition of a technological system or as a characteristic of the existing building conditions. In other 
words, the first approach involves the elaboration of a project, while the second one the management of the actual conditions.

Looking into the first approach related to the project evaluation, the guidelines for the drafting of the preliminary project document [3] address the use compatibility evaluation through the comparison of the use requirements with the building characteristics and its relationships with the context. Accordingly, the evaluation is based on in-depth analysis both of the use requirements and the building potentials and limits. In this way, the reuse project is able to guarantee the fulfilment of the user needs in compliance with the conservation constraints and the technical quality of the project.

The flexibility evaluation method proposed by Di Battista et al. [4] follows the same principles. The method provides the selection of the use destinations according to external and internal relations. The former category takes into consideration the activity requests at urban level as well as their potential negative impacts. Whereas the latter regards the building level and examines firstly the existent values and the conservation building objectives, secondly the performance of the building (in relation to the safety, accessibility, well-being and management aspects), and thirdly the flexibility of the environmental and technological systems. The proposed method suggests a decision-making approach which proceeds gradually by limiting the various alternatives through the evaluation of the compatible performance improvement (i.e. obtained with the minimum physical transformation and in particular with the minimum material loss) and its comparison with the corresponding requirements.

The Resilience Evaluation method (REM) elaborated by Morandotti [5] consists in the evaluation of the adequacy of a new function according to the sustainability of the transformations on the existing building. Starting from a performance assessment of the existing building, the analysis defines a synthetic indicator - the Performance Adequacy Value - and provides an evaluation score based on four parameters, i.e. usability, comfort, safety and accessibility. At a further step it is defined the Resilience Threshold Value by determining the impact of transformation design solutions on the existing building through the evaluation of eight parameters such as material removal, structural alteration, spatial alteration, identity weakening, safety increase, carbon footprint reduction and design for all. What emerges from the proposed method is the introduction of a quantitative approach to the preliminary design phase that allows the measurement of a project impact on a building.

Another contribution to the compatibility evaluation is given by the Architectural Impact Assessment. This method frames the research question of the building transformation limits by adapting the Environmental Impact Assessment procedure to the sector of building heritage [6]. Through the introduction of architectural indicators, which record the modifications in respect to materials, constructive techniques, and form, the aim is to quantify and compare the impact i.e. the advantages and the drawbacks of the various project alternatives. What determines this evaluation is the weight given both to the impact and to the affected building component. Furthermore, the results obtained by this operation is possible to acquire a different importance according to the criteria imposed by the decision-making process.

The scope of ICOMOS Guidance on Heritage Impact assessments for Cultural World Heritage Properties [7] consists in assisting the decision-making process related to different projects of large-scale development. The document underlines that independently of the assessment method chosen, what becomes relevant is the consideration of the attributes that convey "Outstanding Universal Value" to a World Heritage Site or, more generally speaking, values to a cultural heritage [8]. As a result, the impact evaluation is determined not only by the scale of change but also by the importance of the attribute. A further consequence regards 
the necessity of a vital link between the attributes of the site and the attributes of the development for valorising the site [7]. In this perspective, understanding significance and using values is of central importance for heritage impact assessment [9].

During the last years, the Multi-Criteria Decision Analysis (MCDA) has been applied in the field of cultural heritage. The presence of a large number of aspects and of diversified nature, often in conflict, and many of them difficult to be quantified has led to the application of multi-criteria techniques to the evaluation of the various alternative projects [10]. Methods such as the Multi-Attribute Value Theory (MAVT), the Analytic Hierarchy Process (AHP), the Analytical Network Process, (ANP), the Fuzzi-set theory, and the Weighted Sum Model (WSM), were used for the selection of reuse alternatives and enhancement strategies [11], [12]. What stands at the base of the methods above is the idea to put in relation the characteristics of a project with the objectives and the preferences (i.e. the attributes or criteria) of the decision-maker.

The methods of compatibility evaluation described above, regard the elaboration of a project and the estimation of its impact on the built heritage, in order to judge its appropriateness. From the analysis, certain common elements emerge. The first two methodologies, flexibility and resilience-based evaluation, follow a performance-based evaluation by taking into consideration the safety, the accessibility, and the well-being requirements, aiming at the performance improvement with the minimum transformation and material loss. Whereas, the next three methods highlight the importance of the significance/value of the elements and of a weighting procedure, necessary to clarify the objectives and the criteria of the evaluation that are always observer- and context-dependent [13].

\section{THE USE COMPATIBILITY APPROACH TO THE MANAGEMENT PLAN}

The second approach to the compatibility concept is related to the management of the actual use conditions of a building and the long-term effects of the users' behaviour [2]. This category places in the middle the importance of continuous control procedures necessary to determine the limits of physical stresses and of risk thresholds due to the human activities [14]. The following methods represent significant examples in this direction based on the determination of carrying capacity and the assessment of risks.

During the 1960s and 1970s, the carrying capacity concept was applied to the models of visitor management for the safeguarding of natural and cultural resources. The idea was to evaluate the impacts resulting from the visitor use, in order to determine the number of visitors that once exceeded the negative effects are manifested. However, it became soon obvious that this kind of estimation is not practicable because of the various involved factors that are related not only to quantitative aspects but also to qualitative considerations [15]. Furthermore, the social aspects associated with the public use request of these resources enlarge the resource perspective of the carrying capacity issues by consideration of human values [16]. As a result, current approaches to visitor use management focus on establishing limits on impacts instead of visitors, or as widely known the limits of acceptable change (LAC). The LAC-based methodologies count the following common elements: the determination of objectives, the identification of impact indicators, the setting up of standards for the definition of the minimum acceptable conditions and the development of a monitoring and management action [15], [16]. Indicative examples of the LAC procedure application are the preventive measures developed within the management plans of the UNESCO World Heritage Sites [17]. What emerges with clarity in these methodologies is the importance of monitoring for the determination of carrying capacity that is considered an ongoing process.

From the experience of U.S. National Parks and the Visitor Experience and Resource Protection (VERP) framework (an adaptation of the LAC process) comes out an operational 
tool for the tourism/recreation management. It consists in management matrices based on classification systems [18]. The first system regards the recreation/tourism impacts and the related problems, while the second considers the management strategies and practices that can be used to address these problems. These classification systems can be combined into a series of matrices, offering in this way a more systematic approach to guiding recreation and tourism management.

The Pressure-State-Response (PSR) model developed by the Organisation for Economic Co-operation and Development (OECD) - examples of adjusted versions of the model are the Driving force-State-Response (DSR) model used by the Unites Nations Conference on sustainable development (UNCSD) and the Driving force-Pressure-State-Impact-Response (DPSIR) model used by the European Environment Agency (EEA) - is based on a system of indicators able to integrate environmental, social and economic aspects in a way useful for decision makers in the field of strategic assessment [19]. The model has been proposed in the guidelines elaborated by the Italian Ministry of Culture for the management plan of World Heritage Sites [20]. Specifically, the document applies the analytical and interpretative system of indicators to the evaluation process of the management strategies and actions. The cause-effect relationships pointed up by the model contribute to the better understanding of the impacts caused by the human activities and the development of the necessary strategies to prevent and mitigate them. Another model of critical analysis able to support the identification of strategies, proposed by the same document, is the Strengths-Weaknesses-Opportunities-Threats (SWOT) matrix. This kind of analysis is particularly relevant for the cultural heritage seeing that it provides an effective integration of conservation and valorisation strategies.

The integration between conservation and access promoted by the National Trust strategy bases on the statement that "preservation may always permit of access, while without preservation access becomes for ever impossible" [21]. In recent years, 2007-2010, Trust's objectives focused on maximizing sustainable access to properties by measuring three factors, the social benefits, the conservation benefits and the financial costs [22]. This approach, called Triple Bottom line, incorporates various planning tools and processes.

One of them, the Conservation for Access (C4A) toolkit was developed for balancing conservation and access. The method highlights the importance of the required economic resources for the opening of historic houses to the public. In fact, to prevent damages from the visitor use refers to the existence of adequate housekeeping hours, numbers of staff and equipment proportional to the number of visitors and the timing of use [22]. The measure of the real costs compared to the required ones indicates the sustainability or not of public use. Therefore, any extension of the opening hours and the consequent income increase should be evaluated with respect to the increased resources needed in order to inform decision-making.

What comes out from the examples taking into consideration above is that the elaboration of formal procedures based on the concept of carrying capacity regard mainly the visitor management of natural and cultural heritage sites. Other examples of similar procedures focusing on risk analysis can be found in the field of museums and their collections. In respect of built heritage, we can notice that the application of evaluation models, such as SWOT analysis, DPSIR model, Risk Map model, concerns principally the planning of strategical actions at an urban and territorial level.

\section{CONCLUSIONS}

The study highlights the existence of a large number of methodologies, which derive from diverse scientific fields and their application to the sector of cultural heritage. What brings 
them together is their attempt to measure and evaluate the impacts on cultural heritage caused by the user's requirements providing evidence base for the decision-making.

The term of compatibility and its sense is amplified by concepts such as flexibility, resilience, adaptability, carrying capacity, vulnerability, acceptability, sustainability, demonstrating in this way the necessity for a holistic vision of the question through the consideration of the multiple factors involved.

In particular, the assessment of values/significance obtains a central role in the process of use compatibility evaluation, enabling an effective integration of conservation and valorisation practices. Looking at the social and economic aspects, the use compatibility becomes broader and strictly related to the sustainability evaluation.

In this perspective, the formal evaluation methods based on weighting procedures become mandatory for the clarification of the objectives and of the evaluation criteria that are always observer- and context-dependent.

\section{REFERENCES}

[1] Watt, D.S., Building Pathology. Principles and Practice, Wiley-Blackwell: Oxford, 1999.

[2] Della Torre, S., Riflessioni sul principio di compatibilità: verso una gestione dell'incompatibilità. Atti del convegno "Dalla reversibilità alla compatibilità" Ex Convento di San Francesco Conegliano, 13-14 giugno 2003, Nardini: Firenze, pp. 2732, 2003.

[3] Catalano, M. \& Pracchi, V., La redazione del documento preliminare alla progettazione per i beni culturali, Maggioli editore: Santarcangelo di Romagna, 2012.

[4] Di Battista, V., Fontana, C. \& Pinto, M.R., Flessibilità e riuso, Alinea editrice: Firenze, 1995.

[5] Morandotti, M., Planning the re-use sustainability through resilience evaluation. Reflections on cultural heritage theories and practices. Proceedings of the International Conference on Innovative Built Heritage Models and Preventive Systems (CHANGES), Leuven 6-8 February 2017, eds K. Van Balen \& A. Vandesande, pp. 21-28, CRC/Balkema: Leiden, 2018.

[6] Chiovaro S., Il tema della compatibilità d'uso: nuovi apporti metodologici. Tema, 2, pp. 67-72, 1995.

[7] ICOMOS, Guidance on Heritage Impact Assessments for Cultural World Heritage, ICOMOS: Paris, 2011.

[8] ICOMOS, The Burra Charter. The Australia ICOMOS Charter for the Places of Cultural Significance, ICOMOS: Australia, 2013.

[9] Clark, K., Values-based heritage management and the heritage lottery fund in the UK. APT Bulletin: The Journal of Preservation Technology, Special issue on values-based preservation, 45(2/3), pp. 65-71, 2014.

[10] Miccoli, S., Trattato di restauro architettonico, vol. 4, UTET: Torino, 1996.

[11] Ferretti, V., Bottero, M. \& Mondini, G., From indicators to composite indexes: An application of the multi-attribute value theory for assessing sustainability. Advanced Engineering Forum, 11, pp. 536-541, 2014.

[12] Oppio, A., Bottero, M., Ferretti, V., Fratesi, U., Ponzini D. \& Pracchi, V., Giving space to multicriteria analysis for complex cultural heritage systems: The case of the castles in Valle D'Aosta region, Italy. Journal of Cultural Heritage, 16, pp. 779-789, 2015.

[13] Della Torre, S. \& Petraroia, P., Integration of maintenance and management activities with authorization procedures for listed architectural heritage. Proceedings 
Maintenance Management 2007. Third International Conference on Maintenance and Facility Management, Rome, pp. 87-90, 2007.

[14] Strlič, M., Thickett, D., Taylor, J. \& Cassar, M., Damage functions in heritage science. Studies in Conservation, 58(2), pp. 80-87, 2013.

[15] Pedersen, A. (ed.), Managing Tourism at World Heritage Sites: A Practical Manual for World Heritage Site Managers, UNESCO: Paris, 2002.

[16] US Department of the Interior, National Park Service, Denver Service Center, VERP The Visitor Experience and Resource Protection framework. A Handbook for Planners and Managers, US Department of the Interior, National Park Service, Denver Service Center: Denver, 1997.

[17] Borgarino, M.P., Le strategie di prevenzione nei piani di gestione dei siti Unesco. Riferimenti, esperienze e tendenze in atto. Scienza e beni culturali XXVI, Bressanone 2010, Pensare la prevenzione. Manufatti, Usi, Ambienti, Arcadia ricerche: Venezia, pp. 183-192, 2010.

[18] Manning, R.E. \& Anderson, L.E., A systematic approach to managing recreation and tourism in US National Parks and related areas: development and application of management matrices. Extended Abstracts of the International Colloquium: Management and Carrying Capacity at World Heritage Sites in China, 17-19 May 2013, Mogao Grottoes, Dunhuang, eds N. Agnew \& M. Demas, pp. 39-45, The Getty Conservation Institute: Los Angeles, 2014.

[19] OECD Organisation for Economic Co-operation and Development, OECD Environmental Indicators. Development, measurement and use, reference paper, 2003.

[20] Ministero per i beni e le attività culturali, Il modello del piano di gestione dei beni culturali iscritti alla lista del Patrimonio dell'Umanità. Linee Guida, 2004.

[21] Lithgow, K., Lloyd, H. \& Staniforth, S. (ed.), The National Trust Manual of Housekeeping, Elsevier: London, 2006.

[22] Lithgow, K., Staniforth, S. \& Etheridge, P., Prioritizing access in the conservation of Nation Trust Collections. Studies in Conservation, 53, pp. 178-185, 2008. 